\title{
Invitation to Attend the Fall Meeting of the Swiss Chemical Society in Zurich, on Thursday, September 11, 2008
}

Welcome to the Fall Meeting 2008 of the Swiss Chemical Society. As in previous years, we invite you to attend!

The Fall Meeting is the annual congress of the members of the Swiss Chemical Society and its Divisions. In particular young researchers in the field of chemistry are encouraged to present and exchange scientific results here.

Two years ago, the Swiss Polymer Group participated in this meeting for the first time. Since then it has become a division of this society, the Division of Polymer and Colloids, and it indeed contributes significantly in broadening the range of interests at this meeting, in particular with respect to materials science. We are glad to have them here again.

It is worth mentioning that the number of submitted scientific contributions has reached almost 500 this year, which is, to the best of our knowledge, a new record. It shows that the Division of Chemical Research - the Division that actually takes the main responsibility for the Fall Meeting - is conceptually on the right track and the meeting is well recognized by the science community. Of course, there have been discussions about future directions for the Fall Meeting. Because participation has increased every year it was suggested that the meeting should be extended to a second day. However, the Division of Chemical Research decided for good reason to stay with the traditional concept of a one-day meeting, even if the time frame for all the activities is becoming tighter and tighter. As a consequence, this year's meeting has been extended by three hours in comparison to the 2001 meeting, when the Institute of Inorganic Chemistry took over the organization of the Fall Meeting in Zurich for the first time.

Needless to say that when such an annual event grows along with a growing society, various new activities can not be excluded. Therefore the 2008 Fall meeting will 'as usual' present the prestigious Paracelsus Prize awarded to Prof. Ben Feringa from Groningen. The Werner Prize of the Swiss Chemical Society will be presented to Prof. Jeroen van Bokhoven (ETH Zürich), while Prof. Alexander Heckel (Uni Frankfurt/Main) is awarded the Gramaticakis-Neumann Prize of the Photochemistry Group. For the first time, the winners of the Dr. Max Lüthi Award of the Swiss Chemical Society will received their award during the Fall Meeting. They are Caroline Emery, Daniel Mesitschek and Pitt Allmendinger. Our warmest congratulations to all of them.

\section{Announcements of Other Changes in the General Programme}

- The General Assembly of the Swiss Chemical Society will take place this year for the first time during the Fall Meeting. So, this time there are not only scientific reasons to attend the meeting, since it is considered a duty for the members of the society to participate in the General Assembly and decide on future activities. 
- There is a long tradition of other well-established activities of the Fall Meeting and we should not forget to mention these. First of all the Fall Meeting is indeed dedicated to a large part to young scientists and many of them will be presenting their first talks or posters at this event. As in previous years, the SCS Mettler-Toledo Awards will be awarded to the best speakers during the meeting, whereas the Swiss Chemical Society will honor outstanding poster contributions. This valuable custom must be preserved! But aside from the PhD students and the prize winners we have also invited senior scientists to share their advanced chemistry achievements with us. These invitations are activities of the Divisions with the objective of promoting science in Switzerland and emphasizing the presence of top-notch science at this meeting. So, we are expecting Omar Yaghi from the University of California, Los Angeles as an interdisciplinary guest speaker. Together with our local speaker Paul Pregosin from ETHZ a scientifically outstanding programme has been established for the Minisymposium of Inorganic Chemistry.

- Furthermore, the very well-known scientists Hans Maurer (University of Homburg/ Saar) and Peter Schurtenberger are the guest speaker of the Division of Analytical Chemistry and the invited speaker of the Division of Polymers and Colloids, respectively.

Finally let us address another topic. A Fall Meeting of the this size needs financial support and voluntary work from many people. Therefore, we would like to thank all our sponsors, especially Mettler Toledo and the member companies of the KGF (Kontaktgruppe für Forschungsfragen), Ciba, Novartis, F. Hoffmann-La Roche, Merck Serono, and Syngenta for their financial support. Many other companies are participating in the exhibition section, thus increasing attractivity and revenues of the Swiss Chemical Society as a whole and specifically of the Division of Chemical Research. In particular we would also like to thank the University of Zurich for its substantial contribution in providing the infrastructure and other assistance in organizing this meeting. And of course let me thank all the helpers in the Divisions and Sections of the Swiss Chemical Society. We are grateful to Dr. Ferdinand Wild, Mrs. Bea Spichtig, Mrs. Nathalie Fichter and Mrs. Susanna Sprokkereef in the offices of the Institute of Inorganic Chemistry, many students and helpers from the University of Zurich and the CHIMIA team.

And finally a few words about Prof. Paul Pregosin, who very successfully organized the above-mentioned Minisymposium in Inorganic Chemistry for many years. He has also contributed much work and efforts to the Section of Inorganic and Coordination Chemistry within the Division of Chemical Research. This year he has done all this for the last time, since he intends to retire. Thank you Paul, for all the work you have done for us.

Again, we invite all of you most cordially to attend this meeting on behalf of the Division of Chemical Research, the Swiss Chemical Society and the local Organizing Committee, but also with our warm and personal welcome to you. Thank you for your decision to come and participate.

Looking forward to meeting you in Zurich.

$\begin{array}{ll}\text { Frédéric Merkt } & \text { Heinz Berke } \\ \text { Chairman } & \text { Chairman } \\ \text { Division of Chemical Research } & \text { SCS Fall Meeting } 2008\end{array}$

